\title{
REPRODUCIBILITY OF S2-ALAR ILIAC SCREW MORPHOMETRIC ANALYSIS
}

\section{REPRODUTIBILIDADE DA ANÁLISE MORFOMÉTRICA DO PARAFUSO S2-ASA DO ILÍACO}

\author{
Mariana Demétrio de Sousa Pontes ${ }^{1}$ (D), Lucas américo Francisco ${ }^{1}$ (iD, LUCas KLarosk ISMael ${ }^{1}$ (i), \\ Carlos Fernando Pereira da Silva Herrero ${ }^{1}$ i] \\ 1. Universidade de São Paulo, Ribeirão Preto School of Medicine, Department of Orthopedics and Anesthesiology, Ribeirão Preto, SP, Brazil.
}

\section{ABSTRACT}

Objective: To evaluate the reproducibility of a S2-alar iliac (S2AI) screw parameters measurement method by inter and intraobserver reliability. Methods: Cross-sectional study, considering computed tomography exams. Morphometric analysis was performed by multiplanar reconstructions. Screw length, diameter and trajectory angles were the studied variables. To analyze the measurements reproducibility, intraclass correlation coefficient (ICC) was used. Results: Interobserver reliability was classified as strong for screw shortest length (ICC: 0.742) and diameter (ICC: 0.699). Interobserver reliability was classified as moderate for screw longest length (ICC: 0.553 ) and for screw trajectory angles in the axial plane for the longest (ICC: 0.478) and for the shortest lengths (ICC: 0.591). Intraobserver reliability was interpreted as excellent for screw shortest (ICC: 0.932) and longest lengths (ICC: 0.962) and diameter (ICC: 0.770 ) and screw trajectory angles in the axial plane for the screw longest (ICC: 0.773) and shortest lengths (ICC: 0.862). There were weak interobserver and strong intraobserver reliabilities for trajectory angle in sagittal plane, but no statistical significance was found. Conclusion: Inter and intraobserver reliability of S2AI screw morphometric parameters were interpreted from moderate to excellent in almost all studied variables, except for the screw trajectory angle in the sagittal plane measurement. Level of Evidence IV, Diagnostic Studies - Investigating a Diagnostic Test.

Keywords: Spine. Sacroiliac Joint. Sacrum. Tomography. Reproducibility of Results.

\section{RESUMO}

Objetivo: Avaliar a reprodutibilidade, por meio da concordância inter e intraobservador, de um método de aferição dos parâmetros sacropé/vicos do parafuso S2-asa do ilíaco (S2Al). Métodos: Estudo transversal, considerando exames de tomografia computadorizada. A análise morfométrica foi feita por meio de reconstruções multiplanares. As variáveis estudadas foram: comprimento, diâmetro e ângulos de trajetória do parafuso S2AI. Para análise da reprodutibilidade das medidas, utilizou-se o coeficiente de correlação intraclasse (ICC). Resultados: A confiabilidade interobservador foi classificada como forte para o menor comprimento (ICC: 0,742) e diâmetro (ICC: 0,699). Em relação ao maior comprimento (ICC: 0,553) e aos ângulos de trajetória axial para o maior (ICC: 0,478) e para o menor comprimento (ICC: 0,591), a confiabilidade interobservador foi classificada como moderada. A confiabilidade intraobservador foi excelente para o menor (ICC: 0,932) e maior comprimentos (ICC: 0,962), diâmetro (ICC: 0,770) e ângulos de trajetória axial (ICC: 0,773 - maior comprimento; ICC: 0,862 - menor comprimento). Houve confiabilidade interobservador fraca e intraobservador forte para o ângulo de trajetória sagital, porém sem significância estatística. Conclusão: A correlação inter e intraobservador dos parâmetros morfométricos do parafuso S2Al mostrou-se de moderada a excelente em quase todas as variáveis estudadas, exceto para o ângulo de trajetória sagital. Nível de Evidência IV, Estudos diagnósticos - Investigação de um exame para diagnóstico.

Descritores: Coluna Vertebral. Articulação Sacroilíaca. Sacro. Tomografia. Reprodutibilidade dos Testes.

Citation: Pontes MDS, Francisco LA, Ismael LK, Herrero CFPS. Reproducibility of S2-alar iliac screw morphometric analysis. Acta Ortop Bras. [online]. 2021;29(2):97-100. Available from URL: http://www.scielo.br/aob.

\section{INTRODUCTION}

Long instrumentation in the spine, which includes the sacrum, requires additional pelvic fixation in order to minimize the high failure rates when the S1 pedicular screw is used alone distally. ${ }^{1-4}$ In this context, several techniques of spinal pelvic fixations were described to add stability and rigidity to instrumentation, including transiliac bars, iliac screws and sacroiliac screws. ${ }^{5-8}$

Relatively newer, the S2-alar Iliac screw (S2AI) technique has been developed and has been recognized as a viable sacropelvic fixation option. ${ }^{1,9}$ The minor dissection necessary for the insertion

All authors declare no potential conflict of interest related to this article.

The study was conducted at Hospital das Clínicas of the Ribeirão Preto School of Medicine, Universidade de São Paulo.

Correspondence: Mariana Demétrio de Sousa Pontes. Avenida Bandeirantes, 3900, Vila Monte Alegre, Ribeirão Preto, SP, Brazil, 14049900. marianadpontes@gmail.com 
of this screw; the less prominence of the implant, with consequent lower rates of dehiscence and infection of the surgical wound; and the elimination of the need for modular connectors, since the entry point of the S2AI screw is in line with proximal fixation, are some of the benefits in relation to other techniques. , $^{1,9-12}$

Although the literature has suggested anatomical parameters for the use of the S2AI screw, 3,4,10,11 there are gaps concerning the reliability of these findings. The aim of this study is to evaluate the reproducibility, through the analysis of inter and intraobserver agreement, of a way of evaluating the sacropelvic parameters necessary for the safe insertion of the S2AI screw.

\section{MATERIALS AND METHODS}

The research project was approved by the Research Ethics Committee of the institution, including the exemption from the informed consent form, with process no. $788 / 2019$ (CAAE: 08968219.4.0000.5440).

This is a cross-sectional observational study, considering computed tomography (CT) of the pelvis. Inclusion criteria were the 100 most recent pelvis CTs in the institution's archive, patients over 18 years of age and of both sexes. Of these consecutively selected tests, 66 were met by the exclusion criteria because they had undergone previous surgery in pelvic or lumbosacral region and/or pathologies affecting the sacropelvic segment (fracture, tumor, infection, congenital anomaly, ankylosing spondylitis), totaling $n=34$ cases, of which 18 are male and 16 female, whose age ranged from 18 to 86 years, with a mean of 52.11 years, median of 57.5 years and standard deviation (SD) of 18.56 years. The tests were performed on the multislice computed tomography devices of the institution (Philips ${ }^{\circledR}$ Big Bore 16, Netherlands and Toshiba ${ }^{\circledR}$ Aquilion 64, Japan), with field of view protocol (FOV) $500 \mathrm{~mm}, 120 \mathrm{kV}$, milliamperage $(\mathrm{mA})$ varying according to patient weight, cutting thickness and reconstruction interval of $1 \mathrm{~mm}$.

The CTs were downloaded in digital imaging and communications in medicine (DICOM) format, and the images were transferred to Horos $^{\circledR}$ software, version 1.1.7. The images were analyzed in a bone window (window level between 300 and $350 \mathrm{HU}$ ) and reconstructed in multiplanar models, using the Multiplanar reformatting (MPR) 3D function. The reslicing tool was used to obtain minute anatomical alignment. The variables studied were the following morphometric parameters of the S2Al screw: longer length (LL), shorter length (SL), diameter (DIAM), axial plane trajectory angle (ATA) for the longer length (ATALL), ATA for the shorter length (ATASL) and trajectory angle in the sagittal plane (STA) (Table 1).

Table 1. S2Al screw variables analyzed in this study.

\begin{tabular}{c|c}
\hline S2Al screw parameter & Abbreviation \\
\hline shorter length & SL \\
\hline longer length & LL \\
\hline diameter & DIAM \\
\hline axial trajectory angle for the shorter length & ATASL \\
\hline axial trajectory angle for the longer length & ATALL \\
\hline sagittal trajectory angle & STA
\end{tabular}

The methodology for evaluating the exams was performed as follows: Initially, a multiplanar reconstruction was performed from the median cut of the sagittal plane, with inclination of the axis of the series of axial sections (Figure 1), to find the image, in the axial oblique plane, in which the Vertebra S2 and the anteroinferior iliac spine are seen in the same section (Figure 2). Then, in the oblique coronal reconstruction, the longitudinal axis was adjusted in the center of the pelvis, and the line representing the oblique axial cut, at the midpoint between the foramens of S1 and S2. After that, the STA was measured in relation to the S1 plateau (Figure 3) and the entry point of the S2AI screw was demarcated in the oblique axial reconstruction. The point of entry considered was the midpoint of the posterior cortical of the sacrum between the foramens of S1 and S2. ${ }^{3,13}$ Still in the oblique axial plane, the LL and the SL of the screw were measured (Figure 4), tangentially the internal and external corticals of the iliac, respectively; the largest viable DIAM of the screw, which corresponds to the smallest measure of the virtual space between the inner and outer tables of the iliac (Figure 4); and the ATAs (ATALL and ATASL) in relation to the anteroposterior line, perpendicular to the horizontal line of the pelvis (Figure 5). Knowing that the diameter of the implants is determined by the measurement of the internal screw size, $3.75 \mathrm{~mm}$ (half of the diameter of the chosen implant $(7.5 \mathrm{~mm})$ ) was subtracted medially and laterally so that the screw threads do not violate the iliac bone corticals (Figure 6). Linear parameters were measured in millimeters and angular parameters were measured in degrees.

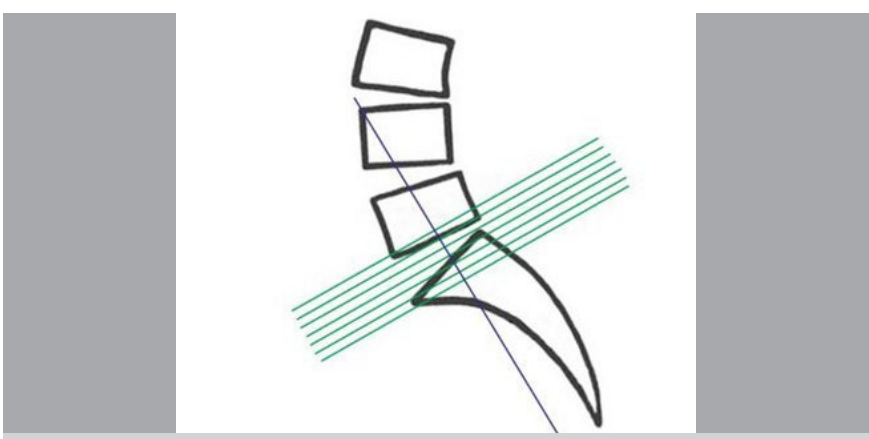

Figure 1. Inclination of the axis (blue) of the series of axial cuts (green), performed to obtain Figure 2.

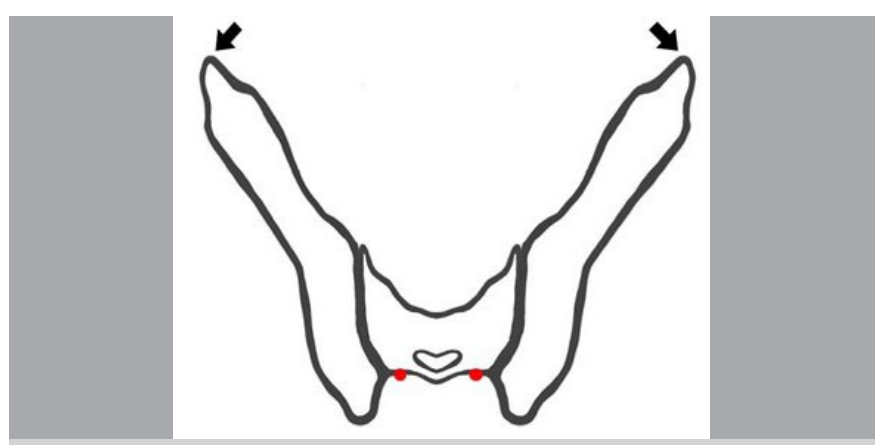

Figure 2. Cut into the oblique axial plane where the entry point of the S2Al screw (red dots) and the anteroinferior iliac spine (arrow) are in the same plane.

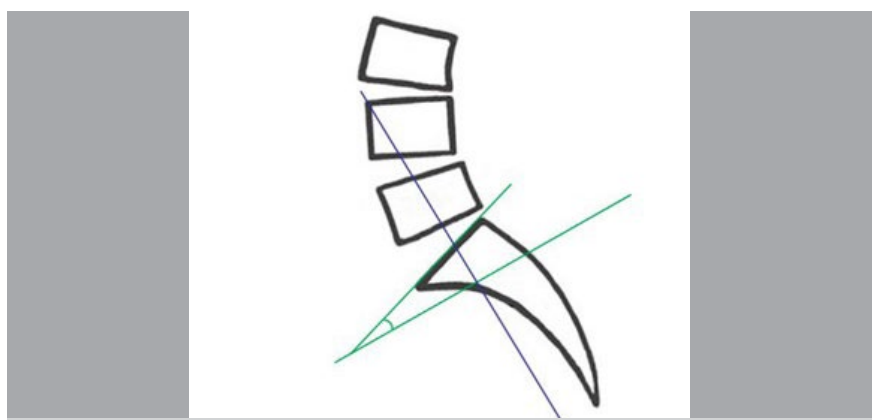

Figure 3. Measurement of the STA in relation to the upper plateau of S1. STA: sagittal trajectory angle 


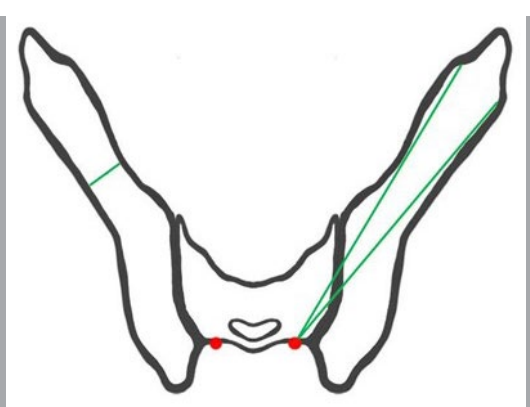

Figure 4. Measurement of $L L$ and $S L$ of the S2AI screw, tangentially with the internal and external corticals of the left ilium, respectively. On the right, we can see the measurement of the largest viable DIAM of the S2Al screw, which corresponds to the smaller thickness of the virtual space between the corticals or ilium. LL: longer length; SL: shorter length; DIAM: diameter.

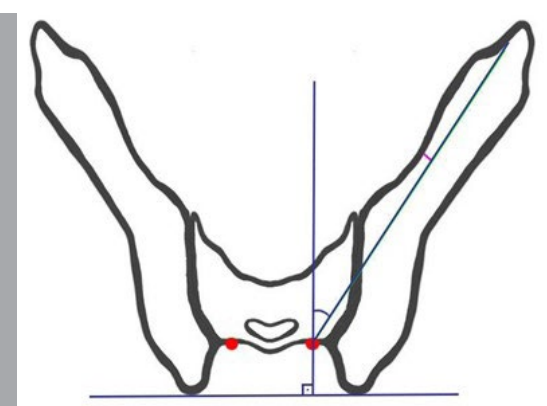

Figure 5. Measurement of the ATA in relation to the anteroposterior blue line of the sacrum, perpendicular to the horizontal line of the pelvis. ATA: axial trajectory angle.

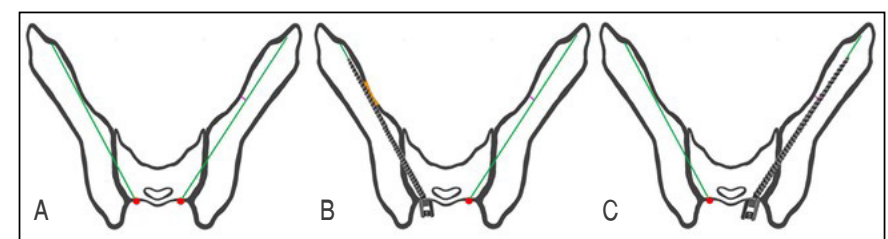

Figure 6. A) LL demarcations of the S2Al screw tangent to the medial cortical of the right iliac bone and with medial subtraction of half the diameter of the implant in the left iliac bone; B) S2Al screw inserted following the planning carried out on the right: Note the violation of the medial cortical of the iliac (orange). C) S2Al screw inserted following the planning carried out on the left: There is no violation of the corticals of the ilium. LL: longer length

All tomographies were analyzed by two researchers. Reseacher 1 , orthopedist and master's student, performed the evaluation of the tomographies in two moments with monthly interval. Researcher 2, medical student in the 5th year, evaluated the exams in a single moment, two weeks after having undergone a training period with researcher 1 , which consisted of a class and three shifts of analysis of the images, following a checklist, with weekly intervals.

The data were tabulated and analyzed in the Microsoft Excel software ${ }^{\circledR}$ version 15.29 and the results were shown in average, maximum and minimum values, SD and confidence interval $(\mathrm{Cl})$, considering confidence level of $95 \%$. For the purpose of analyzing the reproducibility of the measurements, through inter and intraobserver agreement, the data were imported into the IBM SPSS Statistics ${ }^{\circledR}$ version 25 software and the intraclass correlation coefficient (ICC) was used, with the following interpretation: $<0.4$ : weak; from 0.4 to 0.6: moderate; from 0.6 to 0.75 : strong; from 0.75 to 1.0: excellent. The results were considered statistically significant when $p<0.05$.

\section{RESULTS}

In the 34 exams evaluated, LL measurement ranged from 86.8 to $137.5 \mathrm{~mm}$, with an average of $108.9 \mathrm{~mm}(95 \% \mathrm{Cl}$ : $104.96-$ $113.01 \mathrm{~mm}$ ) and SL, from 73.7 to $117.6 \mathrm{~mm}$, with an average of $98.1 \mathrm{~mm}$ (95\%Cl: $94.62-101.72 \mathrm{~mm}$ ). The measurement of DIAM ranged from 9.2 to $21.2 \mathrm{~mm}$, with a mean of $13.8 \mathrm{~mm}(95 \% \mathrm{Cl}: 12.75-14.91 \mathrm{~mm})$. Regarding ATALL, we observed an average of $38.1^{\circ}$ (95\%Cl: $36.12-$ $40.06^{\circ}$ ) and an average variation in relation to ATASL of $3.3^{\circ}$ $\left(95 \% \mathrm{Cl}: 2.79-3.92^{\circ}\right)$. The ATS ranged from 4.8 to $10.2^{\circ}$, with an average of $7.1^{\circ}\left(95 \% \mathrm{Cl}\right.$ : $\left.6.61-7.53^{\circ}\right)$.

The LL measurement of the S2Al screw showed moderate interobserver reliability (ICC: $0.553-95 \% \mathrm{Cl}: 0.231-0.832$ ) and excellent intraobserver reliability (ICC: $0.962-95 \% \mathrm{Cl}: 0.829-0.992$ ). The interobserver reliability found for the SL of the screw was classified as strong (ICC: $0.742-95 \% \mathrm{Cl}: 0.480-0.872$ ) and intraobserver reliability, as excellent (ICC: $0.932-95 \% \mathrm{Cl}$ : $0.690-0.986$ ).

The DIAM of the S2AI screw showed strong interobserver reliability (ICC: $0.699-95 \% \mathrm{Cl}: 0.387-0.851$ ) and excellent intraobserver reliability (ICC: $0.770-95 \% \mathrm{Cl}: 0.096-0.954)$.

Regarding ATAs, there was moderate interobserver reliability for ATALL (ICC: $0.478-95 \% \mathrm{Cl}: 0.040-0.739$ ) and also for ATASL (ICC: $0.591-95 \% \mathrm{Cl}: 0.382-0.909)$. On the other hand, the intraobserver reliability found was excellent for both ATALL (ICC: $0.773-95 \% \mathrm{Cl}$ : 0.235 - 0.958), and ATASL (ICC: 0.862 - 95\%Cl: 0.068 (0.974).

There was weak interobserver reliability (ICC: $0.249-95 \% \mathrm{Cl}$ : $-0.141-0.364$ ) and strong intraobserver reliability (ICC: $0.610-$ 95\%Cl: $0.209-0.918)$ for the STA, but these differences did not present statistical significance $(p>0.05)$.

The results of the study are summarized in Tables 2, 3 and 4.

Table 2. Morphometric parameters of the S2Al screw measured from multiplanar reformations of the CTs.

\begin{tabular}{c|c|c}
\hline Measurement & S2Al screw parameter & Mean SD \\
\hline $\mathrm{mm}$ & $\mathrm{SL}$ & $98.1 \pm 10.55$ \\
\hline & $\mathrm{LL}$ & $108.9 \pm 11.97$ \\
\hline & DIAM & $13.8 \pm 3.21$ \\
\hline degrees & ATASL & $41.1 \pm 6.43$ \\
\hline & ATALL & $38.1 \pm 5.85$ \\
\hline & STA & $7.1 \pm 1.36$
\end{tabular}

SL: shorter length: LL: longer length; DIAM: diameter; ATASL: axial trajectory angle for the shorter length; ATALL: axial trajectory angle for the longer length; STA: sagittal trajectory angle.

Table 3. Interobserver reliability of S2AI screw parameters.

\begin{tabular}{c|c|c}
\hline S2AI screw parameter & ICC $(95 \%$ Cl) & $\boldsymbol{P}$ \\
\hline SL & $0.742(0.480-0.872)$ & $p<0.001$ \\
\hline LL & $0.553(0.231-0.832)$ & $p<0.001$ \\
\hline DIAM & $0.699(0.387-0.851)$ & $p<0.001$ \\
\hline ATASL & $0.591(0.382-0.909)$ & $p<0.05$ \\
\hline ATALL & $0.478(0.040-0.739)$ & $p<0.05$ \\
\hline STA & $0.249(0.141-0.364)$ & $p<0.740$
\end{tabular}

SL: shorter length; LL: longer length; DIAM: diameter; ATASL: axial trajectory angle for the shorter length; ATALL: axial trajectory angle for the longer length; STA: sagittal trajectory angle.

\begin{tabular}{|c|c|c|}
\hline S2Al screw parameter & ICC $(95 \% \mathrm{Cl})$ & $\mathbf{P}$ \\
\hline SL & $0.932(0.690-0.986)$ & $p<0.001$ \\
\hline LL & $0.962(0.829-0.992)$ & $p<0.001$ \\
\hline DIAM & $0.770(0.096-0.954)$ & $p<0.05$ \\
\hline ATASL & $0.862(0.068-0.974)$ & $p<0.002$ \\
\hline ATALL & $0.773(0.235-0.958)$ & $p=0.003$ \\
\hline STA & $0.610(0.209-0.918)$ & $p<0.101$ \\
\hline
\end{tabular}

SL: shorter length; LL: longer length; DIAM: diameter; ATASL: axial trajectory angle for the shorter length; ATALL: axial trajectory angle for the longer length; STA: sagittal trajectory angle. 


\section{DISCUSSION}

In this study, in which the analysis was performed by means of multiplanar tomographic reconstructions with precise anatomical realignment, values similar to those described in the literature in relation to lengths, LL and SL, and DIAM of the S2AI screw were found, since, in a review article, Wu et al. ${ }^{10}$ report that the diameter of viable implants ranges from 6.5 to $8.5 \mathrm{~mm}$ and the length from 65 to $120 \mathrm{~mm}$. In an asian evaluation, Kwan et al. ${ }^{3}$ suggested that screws between 85 and $120 \mathrm{~mm}$ in length are potentially safe based on the study population, with no gender difference. The lateral safety trajectory, i.e., the ATA, was estimated from $39.3^{\circ} \pm 3.1$ to $50.4^{\circ} \pm 6.1$ in men and from $39.5^{\circ} \pm 3.1$ to $50.2^{\circ} \pm 5.9$ in women, and the length range of the screw within this safety trajectory was $85 \mathrm{~mm} \pm 22.2$ to $122.6 \mathrm{~mm} \pm 11.4$ and $86.4 \mathrm{~mm} \pm 22.7$ to $122.2 \mathrm{~mm} \pm 11.9$ for men and women, respectively. ${ }^{3}$

Regarding the values found for implant trajectory angles, the findings of this study differ from the international literature regarding STA. Chang et al., ${ }^{9}$ when evaluating 20 tomographies of the pelvis of adolescents who are closely mature, indicate approximately $40^{\circ}$ of ATA and also $40^{\circ}$ of STA to find the ideal pathway of the S2AI screw, with the potential to minimize the prominence of the implant and simplify the technique for obtaining pelvic fixation, which is very discrepant to the finding of $7.1^{\circ} \pm 1.36$ found in this study. This author, however, did not detail which parameters were used to obtain this STA result. Elder et al. ${ }^{11}$ recommend a similar ATA, from 30 to $45^{\circ}$, and a relatively lower STA, between 20 and $45^{\circ}$. In another study, in which the insertion by minimally invasive technique of the S2Al screw was performed in cadavers, lengths of $90 \mathrm{~mm}$, on average, were possible, ranging from 69 to $120 \mathrm{~mm}$. The mean ATA was $42^{\circ}$ and the STA was also higher, around $29^{\circ} .4$
Based on this discrepancy of values found in relation to the STA, the main responsible factor could be the lack of detail of the measurement technique adopted in these publications. ${ }^{3,4,9,10,11}$ The soil was probably used as a parameter, which may increase the risk of failure, since the patient's positioning and the deformities presented can mask the angular value in relation to the soil, making it unreliable. In addition, we questioned, in an accessory way, about the presence of possible bone anatomical variations of the pelvis of Brazilian individuals. Thus, it is clear the importance of the detailed description of the technique used in the measurement of anatomical parameters, since the comparison of the results becomes unfeasible with different measurement techniques. In this study, measurements were made in an attempt to suggest the upper plateau of S1 as a parameter for the measurement of STA, but the results found do not indicate that this is an ideal parameter for the planning of craniocaudal angulation of the S2AI screw, since both interobserver and intraobserver reliability did not present statistical significance. This study has limitations that deserve to be mentioned: First, this is a study with a small number of tests evaluated; second, the absence of deformity in the selected cases; and, finally, limited clinical application. However, this is the first study in which the inter and intraobserver reliability analysis of the results of the morphometric parameters of the S2Al screw measured by a specific technique was performed.

\section{CONCLUSION}

The inter- and intraobserver correlation of the results of the morphometric parameters of the S2AI screw measured by a specific technique was moderate to excellent in almost all variables studied, except for the measurement of the trajectory angle in the sagittal plane.

AUTHORS' CONTRIBUTIONS: Each author contributed individually and significantly to the development of this article. MDSP: Data collection and analysis, literature review and writing of the article; LAF: acquisition of exams and data collection; LKI: acquisition of exams and data collection; CFPSH: development of the research project, supervision, review of the article and study orientation.

\section{REFERENCES}

1. Hoernschemeyer DG, Pashuck TD, Pfeiffer FM. Analysis of the S2 alar-iliac screw as compared with the traditional iliac screw: does it increase stability with sacroiliac fixation of the spine? Spine J. 2017;17(6):875-9.

2. Edwards CC, Bridwell KH, Patel A, Rinella AS, Berra A, Lenke LG. Long adult deformity fusions to L5 and the sacrum: a matched cohort analysis. Spine. 2004;29(18):1996-2005.

3. Kwan MK, Jeffry A, Chan CYW, Saw LB. A radiological evaluation of the morphometry and safety of S1, S2 and S2-ilium screws in the Asian population using three dimensional computed tomography scan: an analysis of 180 pelvis. Surg Radiol Anat. 2012;34(3):217-27.

4. O'Brien JR, Matteini L, Yu WD, Kebaish KM. Feasibility of minimally invasive sacropelvic fixation percutaneous S2 alar iliac fixation. Spine. 2010;35(4):460-4.

5. Burns CB, Dua K, Trasolini NA, Komatsu DE, Barsi JM. Biomechanical comparison of spinopelvic fixation constructs: iliac screw versus S2-alar-iliac screw. Spine Deform. 2016;4(1):10-5.

6. O'Brien JR, Yu W, Kaufman BE, Bucklen B, Salloum K, Khalil S, et al. Biomechanical evaluation of S2 alar-iliac screws effect of length and quad-cortical purchase as compared with iliac fixation. Spine. 2013;38(20):1250-5.
7. Ramchandran S, George S, Asghar J, Shufflebarger H. Anatomic trajectory for iliac screw placement in pediatric scoliosis and spondylolisthesis: an alternative to S2-alar iliac portal. Spine Deform. 2019;7(2):286-92.

8. Emami A, Deviren V, Berven S, Smith JA, Hu SS, Bradford DS. Outcome and complications of long fusions to the sacrum in adult spine deformity: luque-galveston, combined iliac and sacral screws, and sacral fixation. Spine. 2002;27(7):776-86

9. Chang TL, Sponseller PD, Kebaish KM, Fishman EK. Low profile pelvic fixation: anatomic parameters for sacral alar-iliac fixation versus traditional iliac fixation. Spine. 2009;34(5):436-40.

10. Wu AM, Chen D, Chen CH, Li YZ, Tang L, Phan K, et al. The technique of S2-alar-iliac screw fixation: a literature review. AME Medical J. 2017;2(12):179.

11. Elder BD, Ishida W, Lo SL, Holmes C, Goodwin CR, Kosztowski TA, et al. Use of S2-alar-iliac screws associated with less complications than iliac screws in adult lumbosacropelvic fixation. Spine. 2017;42(3):142-9.

12. Jain A, Brooks JT, Kebaish KM, Sponseller PD. Sacral alar iliac fixation for spine deformity. Spine. 2010;35(20):1887-92.

13. Jost GF, Walti J, Mariani L, Cattin P. A novel approach to navigated implantation of S-2 alar iliac screws using inertial measurement units. J Neurosurg Spine. 2016;24(3):447-53. 